See Article page 36.

\section{Commentary: Hybrid double-valve cardiac surgery: Less time at the pump in a complex setting}

\author{
Matthew A. Romano, MD
}

Innovations in our specialty have afforded us the ability to offer less-invasive procedures while also expanding therapies to those with increased risk. Mitral annular calcification (MAC) is an especially challenging scenario that is being seen with increased frequency. This degenerative process can add significant technical complexity to mitral valve procedures, including perivalvular leak and atrioventricular disruption. MAC has been shown to be an independent predictor of mortality. ${ }^{1}$ Given the successes of transcatheter aortic valve replacement (TAVR), it has become the treatment of choice for aortic stenosis in highrisk patients. Unfortunately, no such reliable transcatheter valve replacement therapy exists to treat calcific mitral valve stenosis, as the realities of left ventricular outflow tract obstruction and significant perivalvular leak continue to be a challenge. Not surprisingly, small series and registry data have shown that results are not as promising as anticipated. ${ }^{2,3}$ And so, the quest continues for an effective less-invasive approach to treat this complex disease.

In this issue of the Journal, Felmly and colleagues ${ }^{4}$ present a compelling "hybrid" approach to treat both aortic and mitral stenosis with MAC in an elderly, 84-year-old high-risk patient. To take advantage of the benefits of less-invasive cardiac surgery and to minimize mitral annular debridement, they performed a robotically assisted mitral valve replacement with a balloon-expandable transcatheter device combined with a TAVR procedure in the

\footnotetext{
From the Department of Cardiac Surgery, University of Michigan, Ann Arbor, Mich. Disclosures: The author reported no conflicts of interest.

The Journal policy requires editors and reviewers to disclose conflicts of interest and to decline handling or reviewing manuscripts for which they may have a conflict of interest. The editors and reviewers of this article have no conflicts of interest.

Received for publication Feb 18, 2020; revisions received Feb 18, 2020; accepted for publication Feb 20, 2020; available ahead of print Feb 27, 2020.

Address for reprints: Matthew A. Romano, MD, Department of Cardiac Surgery, University of Michigan, 5162 Cardiovascular Center, SPC 5864, 1500 E Medical

Center Dr, Ann Arbor, MI 48109 (E-mail: maromano@med.umich.edu).

JTCVS Techniques 2020;2:39-40

2666-2507

Copyright (C) 2020 The Authors. Published by Elsevier Inc. on behalf of The American Association for Thoracic Surgery. This is an open access article under the CC BY-NCND license (http://creativecommons.org/licenses/by-nc-nd/4.0/).

https://doi.org/10.1016/j.xjtc.2020.02.015
}

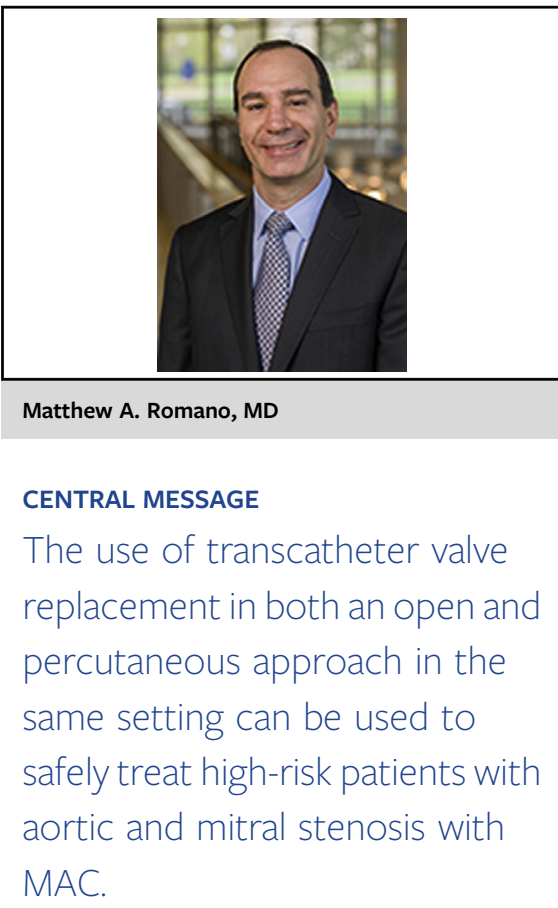

hybrid operating room. The end result was excellent without procedural complications and a relatively short hospitalization. This case report highlights several important points.

As always, the key to success is proper patient selection and extensive preprocedural planning and using a true heart team approach. Aside from the technical considerations, the case presented here demonstrates the importance of diligent preparation and appropriate use of technology. Multidetector computed tomography, although commonplace for aortic valve assessment, is being used more frequently for mitral valve patients with MAC. It not only facilitates sizing of transcatheter prosthesis but also provides valuable anatomic detail, such as the extent of calcification, coronary anatomy, and especially predicting the neo-left ventricular outflow tract.

The use of annular felt reinforcement and a balloonexpandable valve to avoid debridement and replace a mitral valve is not novel. The value of the operation described here is that it takes advantage of technology to significantly reduce crossclamp and cardiopulmonary bypass time and overall procedural time while improving outcome. One would expect that a traditional aortic and mitral valve replacement in a complex patient with MAC, such as the one presented here, would be associated with a lengthy operation, increased risk, and prolonged recovery. By combining a TAVR and a robotic mitral approach for a 
double-valve replacement, the appropriately selected patient may realize the observed benefits of less-invasive cardiac surgery with expedited recovery, less pain, and improved satisfaction. What cannot be understated is the level of expertise and collaboration of specialties that is necessary to successfully execute this type of operation. Indeed, this is not something that can be considered on a whim. Proficiency in robotic cardiac surgery takes significant time and experience. In addition, expertise in mitral surgery, such as those of a reference mitral valve surgeon, proficiency in catheter skills, and partnership with cardiology colleagues, as well as appropriate resources such as a hybrid operating room are essential when contemplating a scenario such as this.

The authors should be commended for promoting a safe and efficient approach to successfully treat a complex, high-risk patient. Less time at the pump is always a good thing and the case reported here can be considered as a viable option to manage challenging patients in a minimally invasive fashion. We should continue to strive for innovative solutions such as this to advance our specialty into the future.

\section{References}

1. Kaneko T, Hirji S, Percy E, Aranki S, McGurk S, Body S, et al. Characterizing risks associated with mitral annular calcification in mitral valve replacement. Ann Thorac Surg. 2019;108:1761-7.

2. Guerrero M, Urena M, Himbert D, Wang DD, Eleid M, Kodali S, et al. 1-year outcomes of transcatheter mitral valve replacement in patients with severe mitral annular calcification. J Am Coll Cardiol. 2018;71:1841-53.

3. Yooh SH, Whisenant BK, Bleiziffer S, Delgado V, Dhoble A, Schofer N, et al. Outcomes of transcatheter mitral valve replacement for degenerated bioprosthesis, failed annuloplasty rings and mitral annular calcification. Eur Heart J. 2019;40: 441-51.

4. Felmly LM, Johnson SD, Steinberg D, Katz MR. Hybrid double-valve replacement. J Thorac Cardiovasc Surg Tech. 2020;2:36-7. 